\title{
MICRO-REPLICATION OF OPTICAL LENSES IN GLASS USING A NOVEL SOL GEL TECHNOLOGY
}

\author{
A. Sayah, V.K. Parashar and M.A.M. Gijs \\ Institute of Microsystems \\ Swiss Federal Institute of Technology Lausanne (EPFL) \\ CH-1015 Lausanne, Switzerland
}

\begin{abstract}
A new method to realize arrays of microlenses using a sol gel glass replication technology is presented. Polydimethyl-siloxane (PDMS) master structures are used for the replication of thin glass membranes, which, by an appropriate annealing procedure, result in converging lenses with positive meniscus. Hereby, we exploit PDMS - sol gel surface interactions and thickness dependent changes in composition of the sol gel solution. The lenses are realized on a circular and square like basis. We characterize the micro-lenses by an optical imaging system and measure their focal length as a function of lens thickness and size. Also spherical aberration effects are measured.
\end{abstract}

\section{INTRODUCTION}

In recent years, sol gel technology has become an important processing technique to fabricate Micro- Opto-Electro-Mechanical Systems (MOEMS), such as micro-lenses. These can be useful components for optical interconnections. The optical elements must be produced at a high dimensional accuracy, high optical quality, but with low cost and at a high production rate. Several fabrication processes of micro-lenses have been reported, including reactive ion etching [1], hot pressing [2], photoresist melting [3], injection molding [2], and the use of photosensitive glasses [4]. In general, a suitable material for a micro-lens is a polymer or a glass. However, the thermal stability of glass makes it the better choice for optical applications at higher temperatures.

The sol gel process is a chemical solution deposition method, which has many advantages for the fabrication of glass micro-components, such as atomic level mixing of highly pure precursors, low processing temperature, tailoring of optical and physio-chemical properties etc. These advantages make it a useful process for the fabrication of optical components for various applications such as wave guides, gratings and electro-optical devices. Several sol gel based methods have been proposed for the processing of optical components: UV light imprinting [5], laser holography [6] and embossing [7].

The present investigation describes the realization of arrays of glass micro-lenses using inhouse developed sol gel materials. PDMS structures are used for the replication of thin glass membranes, which by an appropriate annealing procedure result in converging lenses with positive meniscus. Hereby, we exploit PDMS-sol gel surface interactions and the induced thickness dependent changes in composition of the sol gel solution. These lenses are realized on a circular or square-like basis using flat cylindrical or cubic microstructured PDMS molds, instead of a mold with hemi-spherical (curved) surfaces.

\section{MICROFABRICATION PROCESS}

\section{Sol gel processing}

The sol is prepared through hydrolytic polycondensation of tetra-ethoxysilane, methyltriethoxysilane and vinyl-triethoxysilane in the molar ratio of 50:40:10 in presence of water, solvent and catalyst. The molar ratio of water, solvent and catalyst is 2:2:0.05, respectively, with respect to alkoxides. Methyl and vinyl groups are incorporated in the gel network to make the sol hydrophobic and monolithic. These groups carbonize during heat treatment and result in the formation of a highly cross-linked Si-O-Si glass 


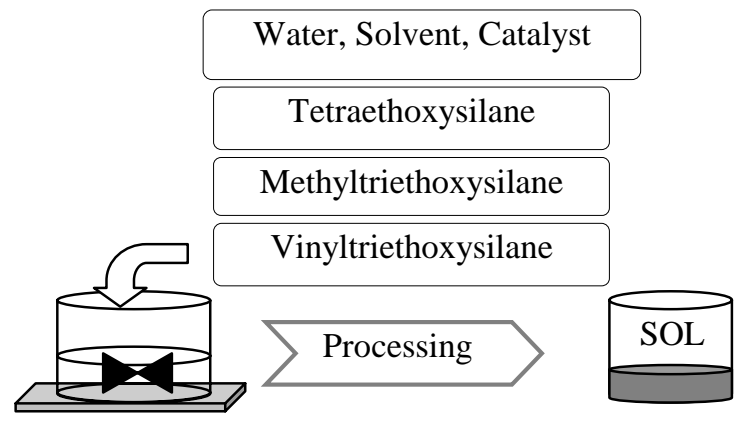

Figure 1 : Schematic of the sol formation process.

network. Figure 1 is a schematic diagram of the sol formation.

The chemistry of the sol gel process includes the hydrolysis and condensation of alkoxides at room temperature, pyrolysis of unhydrolysed alkoxide groups at a temperature between $200-300{ }^{\circ} \mathrm{C}$ and pyrolysis of carbon side chains at a temperature above $350{ }^{\circ} \mathrm{C}$. The overall chemical reaction, representing the hydrolyticpoly-condensation, is shown below :

$$
\begin{aligned}
\mathrm{n} \mathrm{Si}\left(\mathrm{OC}_{2} \mathrm{H}_{5}\right)_{4}+\mathrm{x} \mathrm{H}_{2} \mathrm{O} & \rightarrow \\
-(\mathrm{O}-\mathrm{Si}-\mathrm{O}) n^{-}+ & 4 \mathrm{n} \mathrm{C}_{2} \mathrm{H}_{5} \mathrm{OH}+(\mathrm{x}-2 \mathrm{n}) \mathrm{H}_{2} \mathrm{O}
\end{aligned}
$$

Pyrolysis of unhydrolysed alkoxide groups and organic side groups are shown below :

$$
\begin{array}{lll}
\mathrm{Si}-\mathrm{OC}_{2} \mathrm{H}_{5}+3 \mathrm{O}_{2} & \rightarrow \mathrm{SiOH}+2 \mathrm{CO}_{2}+2 \mathrm{H}_{2} \mathrm{O} \\
\mathrm{Si}-\mathrm{OC}_{2} \mathrm{H}_{5}+\mathrm{SiOH}+3 \mathrm{O}_{2} & \rightarrow \mathrm{SiOSi}+2 \mathrm{CO}_{2}+3 \mathrm{H}_{2} \mathrm{O} \\
& & \\
\mathrm{Si}-\mathrm{CH}_{3}+2 \mathrm{O}_{2} & \rightarrow \mathrm{SiOH}+\mathrm{CO}_{2}+\mathrm{H}_{2} \mathrm{O} \\
\mathrm{Si}-\mathrm{CH}=\mathrm{CH}_{2}+3 \mathrm{O}_{2} & \rightarrow & \mathrm{SiOH}+2 \mathrm{CO}_{2}+2 \mathrm{H}_{2} \mathrm{O} \\
\mathrm{Si}-\mathrm{OH}+\mathrm{Si}-\mathrm{OH} & \rightarrow & \mathrm{Si}-\mathrm{O}-\mathrm{Si}+\mathrm{H}_{2} \mathrm{O}
\end{array}
$$

\section{Replication}

Figure 2 shows the schematic fabrication sequence for arrays of glass micro-lenses. The fabrication process involves two main steps. The first step is the transfer of a microstructure to a PDMS master. The second step is the spin coating with sol gel material on the sacrificial PDMS master. The sol gel structure is dried under vacuum and peeled away from the PDMS master. Subsequently, it is subjected to further heat treatments at higher temperatures, leading to a curved membrane structure. (a)

$\square \square \square \square \square \square$ Si microstructure

PDMS master

(b)

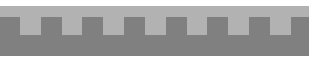

Sol gel material spincoated on PDMS

(c)

Micro-lens array after annealing

Figure 2 : Fabrication sequence for arrays of glass micro-lenses: (a) Preparation of a PDMS master from a silicon microstructure; (b) Spinning of the sol gel material; (c) Production of a curved lens surface by annealing of the sol gel membrane.

\section{CHARACTERIZATION}

The micro-lens arrays are observed by Scanning Electron Microscopy (SEM). The optical efficiency of the micro-lenses is evaluated by an imaging system consisting of a He-Ne laser diode as a light source, an objective and a CCD camera connected to a computer, as shown in figure 3 .

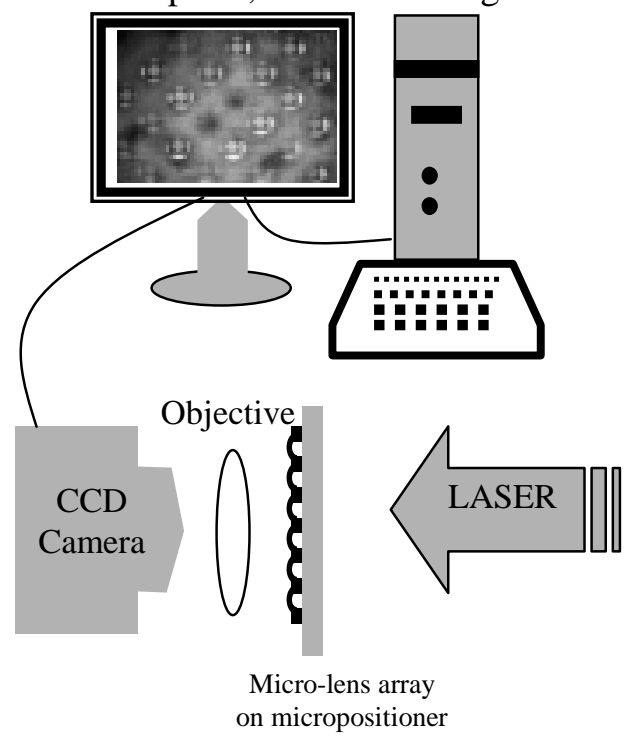

Figure 3 : Schematic diagram of the imaging system to evaluate the micro-lenses. 


\section{RESULTS AND DISCUSSION}

\section{Lens shape characterization}

Micro-lenses, lateral dimensions of which range from $25 \mu \mathrm{m}$ to $300 \mu \mathrm{m}$, are replicated in sol gel derived spin-coated membranes with thicknesses of $80-100 \mu \mathrm{m}$ and $250-300 \mu \mathrm{m}$, resp.. The topography of the lenses after annealing is shown in the SEM pictures of figure 4 for lenses with a square and circular basis. SEM crosssections of these lenses, as shown in figure 5, clearly reflect the formation of a prominent positive meniscus in the films with lower thickness. For the thick membrane of figure 5(a), curvature is very weak, while for the thin membrane of figure 5(b), curvature is more significant. Only the latter type of lenses are further optically characterized.

\section{Optical Properties}

The lenses are characterized by the optical system described above. The laser beam illuminates
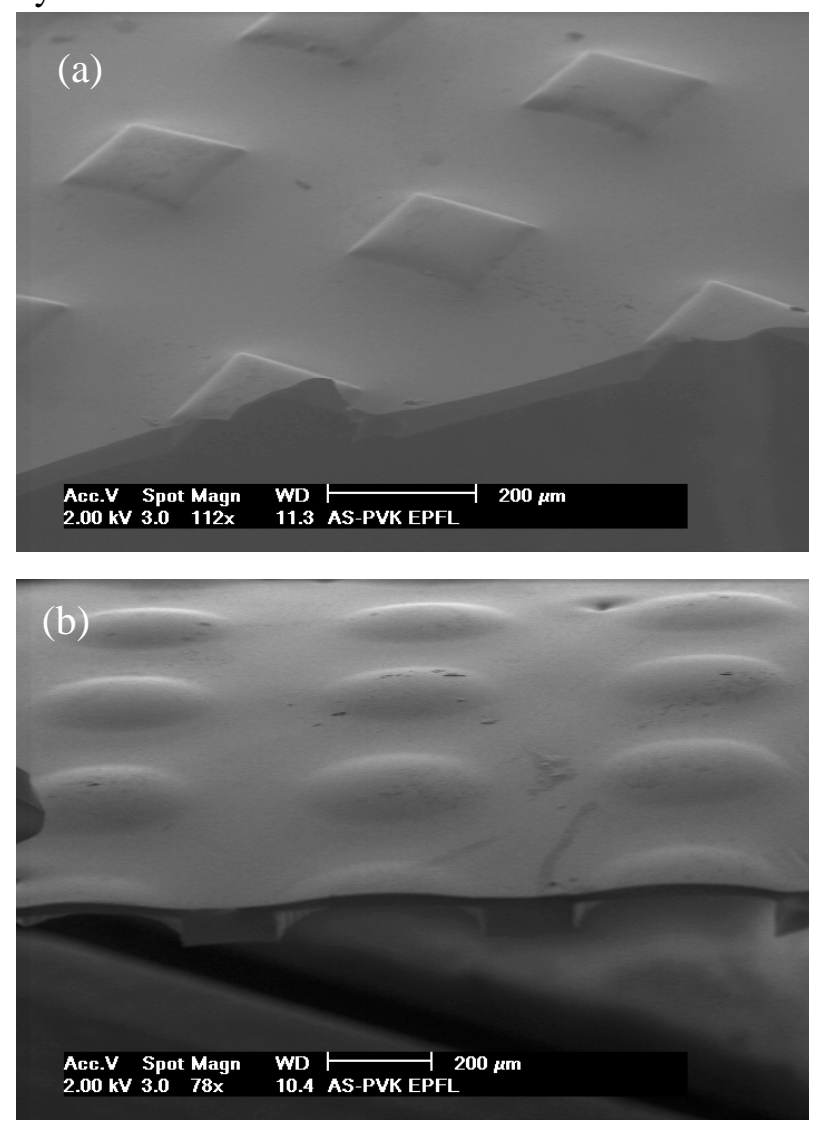

Figure 4 : SEM image of an array of micro-lenses formed from 80-100 $\mu \mathrm{m}$ thin membranes with (a) square and (b) circular shape at the basis. the full area of the surface with the lenses. The intensity profile observed for a single micro-lens with a diameter of $130 \mu \mathrm{m}$ and at $1000 \mu \mathrm{m}$ distance from the surface is shown in figure 6 . We believe these ring-like patterns can be explained by interference effects due to phase differences between refracted laser light originating from different parts of the (totally) exposed lens surface. Figure 7 shows the refracted light distribution formed by an array of micro-lenses with $130 \mu \mathrm{m}$ diameter and interspacing of $450 \mu \mathrm{m}$.

The focal length of each micro-lens is measured by focusing the microscope on the surface of the micro-lens. This location is recorded, then the microscope is moved until the image of an arbitrary object is observed. The image is approximately located at the focal plane of the micro-lens. The difference between these positions is a measure for the focal distance of the tested micro-lens. We show in figure 8 the focal lengths
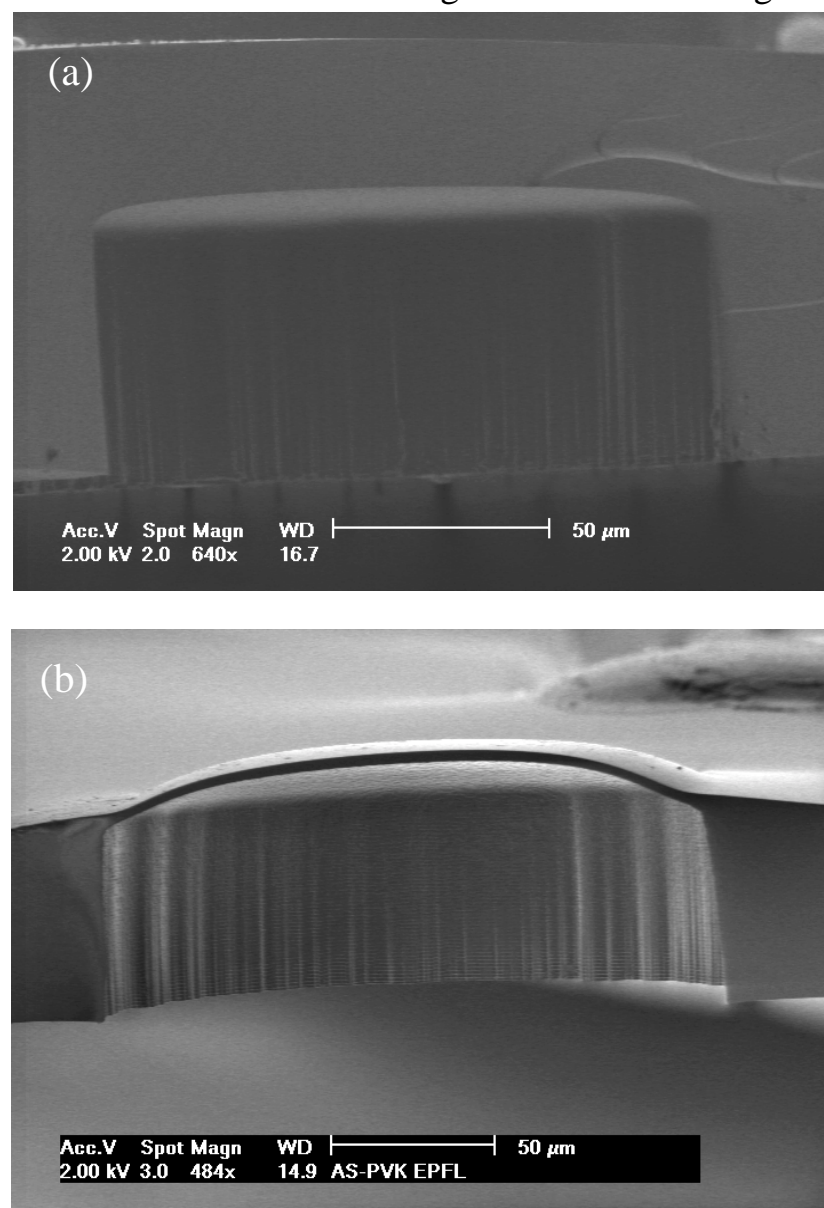

Figure 5: SEM cross-section view of micro-lenses prepared from (a) thick and (b) thin glass membrane films. 


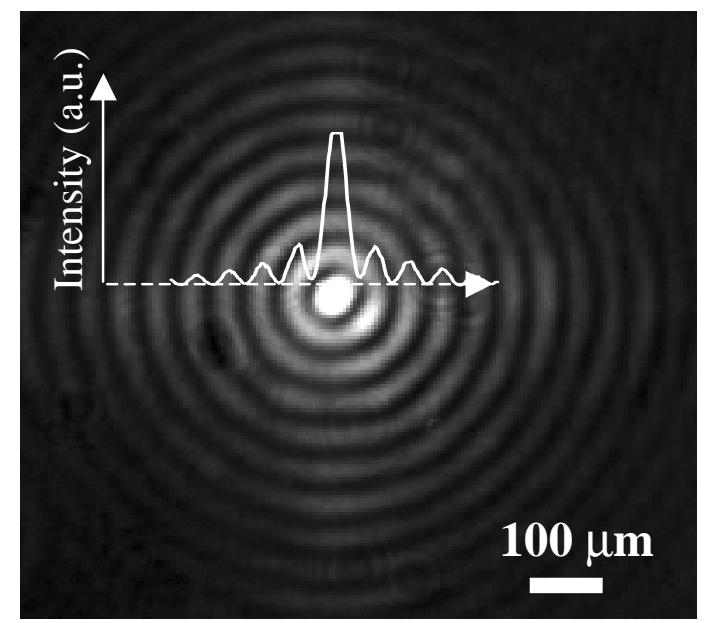

Figure 6 : Intensity profile of an image obtained by a micro-lens with $130 \mu \mathrm{m}$ diameter at a distance of $1000 \mu \mathrm{m}$ from the surface.

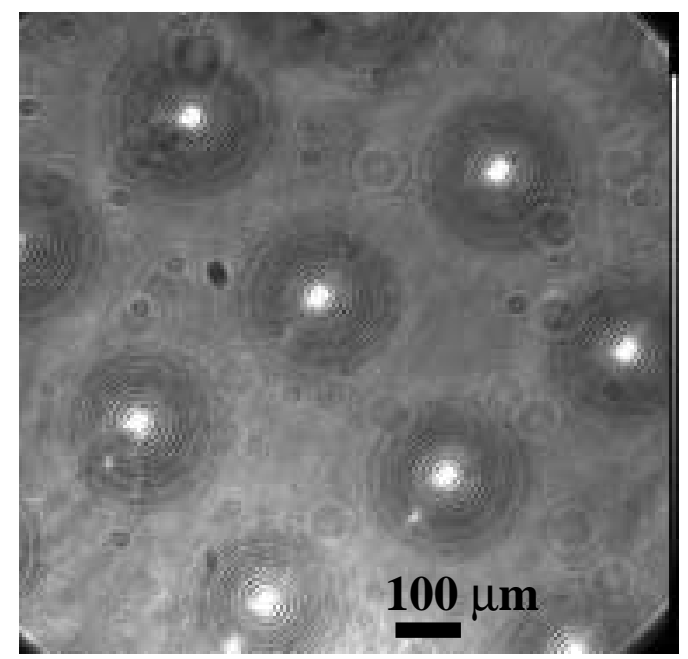

Figure 7 : Optical images from an array of microlenses with $130 \mu \mathrm{m}$ diameter and interspacing of $450 \mu \mathrm{m}$.

for lenses with different diameter. We clearly see that the focal length -and hence the lens curvatureis a nearly linear function of the lens diameter. This can be easily understood, as it is the ratio between membrane thickness and its lateral size, which will determine the effective curvature of the lens. So, both size and membrane thickness are parameters that can be effectively used to produce lenses with a certain focal length.

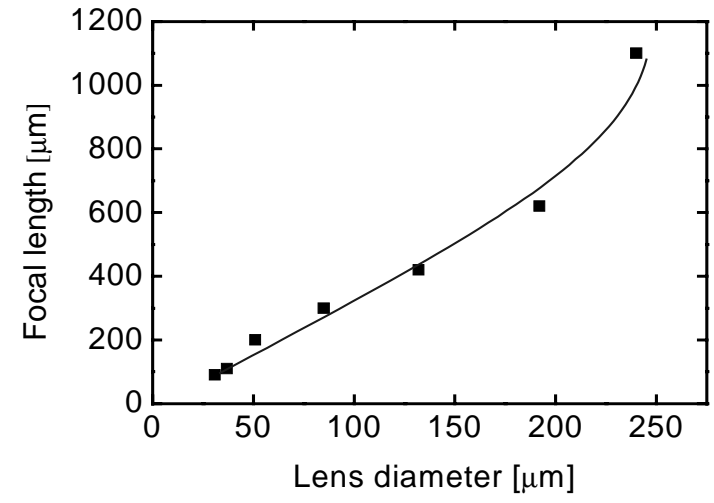

Figure 8 : Focal length of circular microlenses with different diameter.

\section{CONCLUSION}

We have realized arrays of glass microlenses using in-house developed sol gel materials. PDMS masters are used for the replication of thin glass membranes, which, after annealing, result in converging lenses with positive meniscus. The shape and optical properties of these micro-lenses is characterized as a function of lens size and membrane thickness.

\section{REFERENCES}

[1] M.B. Stern, and T.R. Jay, "Dry etching for coherent refractive microlens arrays", Optical Engin. 33, 3547 (1994).

[2] M.T. Gale, "Replication techniques for diffractive optical elements", Microelectronic Engineering 34, 321 (1997).

[3] Ph. Nussbaum, R. Völkel, H.P. Herzig, and R. Dändliker, "Micro-optics for sensor applications", Proc. SPIE 2783, 55 (1996).

[4] V. Lyubin, M. Klebanov, S. Shtutina, N. P. Eisenberg and M. Manevich "Fabrication and testing of microlens arrays for the IR based on chalcogenide glassy resists", J. Non-Crystalline Solids 198-200, 766 (1996).

[5] P. Äyräs, J.T. Rantala, S. Honkanen, S.B. Mendes, and N. Peyghambarian, "Diffraction gratings in solgel films by direct contact printing using a UVmercury lamp", Opt. Commun 162, 215 (1999).

[6] K. Kintaka, J. Nishii, and N. Tohge, "Diffraction gratings of photosensitive $\mathrm{ZrO}_{2}$ gel films fabricated with the two-ultraviolet-beam interference method", Appl. Opt 39, 489 (2000).

[7] J.E. Chisham, M.P. Andrews, C.Y. Li, S.I. Najafi, and A. Malek-Tabrizi, "Gratings fabrication by ultraviolet light imprinting and embossing in a solgel silica glass", Proc. SPIE 2695, 52 (1996). 